\title{
Impact of insecticides on sucking insect pests of cucumber in greenhouse
}

\author{
Farhan Ali Rustamani ${ }^{1}$, Aslam Bukero ${ }^{1}$, Farhad Ali Rustamani ${ }^{1}$, \\ Shahzad Ali Nahiyoon ${ }^{1 *}$, Abdul Aziz Bukero ${ }^{1}$, Dileep Kumar ${ }^{2}$ and \\ Chetram $^{1}$
}

1. Department of Entomology, Sindh Agriculture University, Tandojam, Sindh, Pakistan

2. Institute of Food Sciences and Technology, Sindh Agriculture University, Tandojam, Pakistan

*Corresponding author's email: sanahiyoon@ sau.edu.pk

Citation

Farhan Ali Rustamani, Aslam Bukero, Farhad Ali Rustamani, Shahzad Ali Nahiyoon, Abdul Aziz Bukero, Dileep Kumar and Chetram. Impact of insecticides on sucking insect pests of cucumber in greenhouse. Pure and Applied Biology. Vol. 11, Issue 2, pp397-403. http://dx.doi.org/10.19045/bspab.2022.110039

\begin{tabular}{llll}
\hline \hline Received: 20/04/2021 & Revised: 19/06/2021 & Accepted: 24/06/2021 & Online First: 28/07/2021 \\
\hline \hline
\end{tabular}

\section{Abstract}

Cucumber is a creeper vine vegetable. It belongs to the Cucurbitaceae family that bears cucumiform fruits, which are used as vegetables. There are three main varieties i.e., slicing, pickling, and burpless or seedless. This study was conducted at Millan Agro Seed, Agricultural Research Farm, Tandojam to observe the efficacy of various insecticides against insect pests of cucumber i.e., Bemisia tabaci (Gennadius) and Aphis gossypii (Glover) in greenhouse at different days intervals. The maximum reduction in $B$. tabaci population was recorded as 96.36\% by Imidacloprid and Dimethoate, respectively; followed by Acetamiprid (91.95\%), Bifenthrin (91.76\%), and Cypermethrin $(60.73 \%)$ at 7 DAS. Similarly, the population of $A$. gossypii was reduced to $98.46 \%$ by Dimethoate followed by Acetamiprid (94.66\%), Bifenthrin (91.76\%), Imidacloprid (91.67\%), and Cypermethrin (41.76\%) on the same day (7 DAS), respectively. The ANOVA indicates a significant difference $(\mathrm{P}<0.05)$ between various insecticides and day intervals. However, LSD showed a non-significant $(\mathrm{P}<0.05)$ difference between Imidacloprid and Dimethoate against $B$. tabaci and Imidacloprid and Bifenthrin against $A$. gossypii, respectively. It is concluded that the high population reduction of $B$. tabaci was observed after the application of Imidacloprid and Dimethoate insecticides at 7 DAS. Therefore, Acetamiprid and Bifenthrin insecticides were also displayed a significant reduction against the whitefly population. Similarly, the maximum reduction $\%$ of A. gossypii was showed after the spray of Dimethoate insecticide followed by Acetamiprid, Bifenthrin, and Imidacloprid insecticides on 7 DAS, respectively. The lowest reduction of $B$. tabaci and $A$. gossypii was seen on Cypermethrin insecticide on the same day.

Keywords: Aphis gossypii; Bemisia tabaci; Cucumber; Greenhouse; Synthetic insecticides

Introduction Cucumber (Cucumis sativus L.) is a common vegetable and belongs to the Cucurbitaceae family [1]. The local name of the cucumber is Kheera. This vegetable is commonly used in food as a salad and is also used from digestive aids to beauty products [2]. After cabbage, tomato, and onion, the cucumber is the $4^{\text {th }}$ important vegetable in Asia [3]. More than 50\% yield arises from Asian countries like Iran, Turkey, Japan, Uzbekistan, and Iraq [4]. During the summer season, this vegetable is used as cool food. It includes vitamin C, niacin, calcium, iron, fibers, thiamine, and phosphorous $[5,6]$. In Pakistan, the trade rate of vegetables and fruit was approximately 47895.6 million rupees during the year 2010-11 while, it was 
increased about 66531.3 million rupees during 2015-16 [7]. In Pakistan, the annual usage of vegetables is about $73 \mathrm{~kg}$ per capita while the less depletion is nearly $27.4 \mathrm{~kg}$ [8]. The overall production of cucumber was about 49947 and 50164 tons, and the earning were approximately 14274.6 and $14218.8 \mathrm{~kg} / \mathrm{ha}^{-1}$ during 2012 and 2013 [9]. Bemisia tabaci is not the only attack on vegetables. However, it shows damage to ornamentals plants and field crops particularly in warm and sub-tropical regions [10, 11]. About 600 species of different plants are damaged mainly by whiteflies such as cabbage, cucumber, eggplant, gerbera, gherkin, melon, poinsettia, squash, sweet potato, and tomato [12]. Aphis gossypii is a most destructive insect pest and is found in tropical, subtropical, and temperate areas. It mostly attacks different vegetable leaves like eggplant, potato, tomato, and okra [13, 14]. A. gossypii transmits more than 50 plant viruses which reduce the production of crops and vegetables [15]. Many growers used different insecticides which reduce the high population of insect pests from field crops and vegetables [16]. The spray of Thiamethoxam and Imidacloprid insecticides have reduced the population of sucking insect pests in the field crops [17, 18]. The purpose of this study was to determine the impact of different insecticides at recommended doses as well as a reduction in the population of sucking insect pests.

\section{Materials and methods}

The experiment was conducted at Millan Agro Seed, Agricultural Research Farm, Tandojam. Cucumber variety, MAS-695 was sown on ridges. The plant-to-plant distance was $1 \mathrm{ft}$. and the row-to-row distance was $2 \mathrm{ft}$. The total plot size was 1000 sq. ft. The entire plot was divided into six subplots (130 sq. ft. each), including control. Randomized Complete Block Design (RCBD) was used with four replications. There were five treatments i.e., Imidacloprid $17.8 \mathrm{SL}(1.5 \mathrm{ml} / 1$ lit. water), Cypermethrin $25 \mathrm{EC}(2.5 \mathrm{ml} / 1 \mathrm{lit}$. water $)$, Bifenthrin $56 \mathrm{EC}(1.5 \mathrm{ml} / 1 \mathrm{lit}$. water $)$, Dimethoate $40 \mathrm{EC}(1.4 \mathrm{ml} / 1$ lit. water), and Acetamiprid 20 SP (132 g /1 lit. water) including control (1 lit. water). From each subplot, randomly selected 5 plants for the monitoring of $B$. tabaci and $A$. gossypii. The nymphs and adults of both insect pests were recorded from the top, middle, and bottom portions. The pretreatment data was recorded before the spray of insecticide ( $24 \mathrm{hrs}$.) The posttreatment data were recorded at different intervals i.e., 1, 3, 5, and 7 DAS (Days after Spray). The data were subjected to statistical analysis using Statistix 8.1 computer software [19]. The differences among the treatment's means were compared by the LSD test, where necessary. The population of reduction \% was calculated by using Abbott's formula [20].

Reduction $(\%)=\underline{1-n \text { in } \mathrm{T} \text { after treatment }} \times 100$ $n$ in Co after treatment

\section{Results and discussion}

The pre-treatment population of whitefly per leaf on cucumber is presented in (Fig. 1). The maximum mean population was recorded in the control plot (13.05a) followed by Dimethoate (10.55ab), Acetamiprid (9.85b), Cypermethrin (8.55b), Imidacloprid (8.20b), and Bifenthrin (8.03b) before 24 hrs., respectively. 


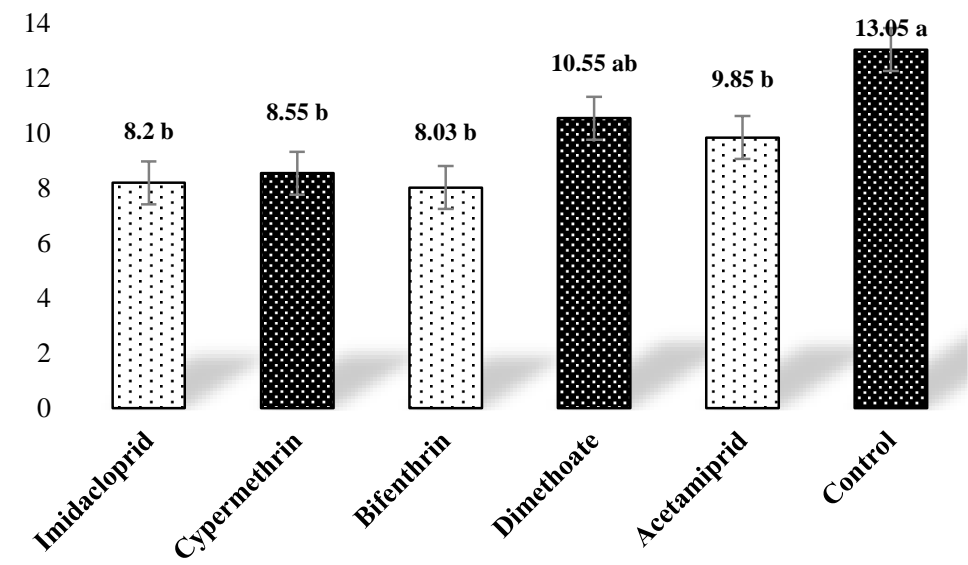

Figure 1. Pre-treatment population of Bemisia tabaci per leaf

The (Table 1) shows the reduction $\%$ and average population of whitefly per leaf on cucumber. The spray of Imidacloprid and Dimethoate insecticides showed the highest reduction $96.36 \%$ on 7 DAS. In contrast, the lowest reduction was seen $71.84 \%$ and $71.07 \%$ at 1 DAS against both insecticides. Similarly, the insecticides (Acetamiprid and Bifenthrin) were also proved as extremely toxic and highly reduced the population $91.95 \%$ and $91.76 \%$ on 7 DAS followed by $88.70 \%$ and $77.97 \%$ at 5 DAS, respectively. The minimum reduction was observed at $60.73 \%$ against Cypermethrin at 7 DAS. The maximum average population was recorded at $7.18 \mathrm{~b}$ on Cypermethrin insecticide at 1 DAS while the minimum mean population was seen $0.35 \mathrm{c}$ on Imidacloprid insecticide at 7 DAS. In control, the maximum mean population was observed 13.28a at 7 DAS and the minimum was displayed 9.93a on 3 DAS. The analysis of variance shows a significant difference $(\mathrm{P}<0.05)$ among different insecticides and intervals, respectively.

Our findings have less conformity with [21] who reported that the Dimethoate insecticide displayed the highest reduction of whitefly (66.80\%) at 7 DAS. However, Acetamiprid and Imidacloprid insecticides showed a 55-59\% reduction on the same interval. We disagreed with [22] who said that the maximum population was reduced 0.02 and $0.03 \%$ after the application of
Imidacloprid and Dimethoate as compared to Dinotefuran $(0.08 \%)$ at 10 DAS. According to [23] who determined that the Curacran showed a maximum reduction of $85.11 \%$ as compared to Bifenthrin insecticide of $81.86 \%$ on whiteflies population. Our findings have surety with [24] who examined that the Cypermethrin insecticide seen lowest reduction after 7 DAS. [21] mentioned that the Dimethoate insecticide $(65.19 \%)$ reduction followed by Acetamiprid (53.89\%) at 3 DAS. [25] reported that the Cypermethrin insecticide showed their impact on whiteflies after 10 days of spray. After the $1^{\text {st }}$ spray of different insecticides, the reduction of $B$. tabaci was observed at 17 to $23 \%$ during the $5^{\text {th }}$ day and 15 to $21 \%$ after the $7^{\text {th }}$ day, respectively [26].

The (Fig. 2) depicts the pre-treatment population of aphid per leaf on cucumber. Before $24 \mathrm{hrs}$. of treatment, the highest average population was observed in the untreated plot (27.60a) and the lowest was seen on the Bifenthrin plot (16.73b). The reduction $\%$ and mean population of aphid per leaf are mentioned in (Table 2). The maximum population was decreased after the spray of Dimethoate $(98.46 \%)$ and Acetamiprid $(94.66 \%)$ at 7 DAS as compared to Bifenthrin $(91.76 \%)$ and Imidacloprid (91.67\%), respectively. Similarly, Imidacloprid insecticide significantly reduced the population $(87.77 \%)$ followed by Bifenthrin (81.23\%) 


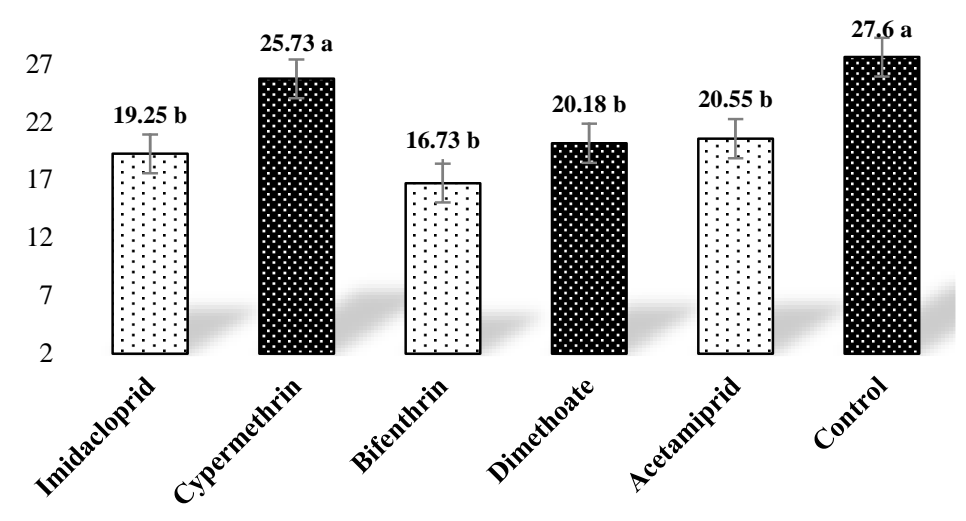

Figure 2. Pre-treatment population of Aphis gossypii per leaf

at 3 DAS. The least reduction was showed $41.76 \%$ when treated the Cypermethrin insecticide on 7 DAS as compared to $34.33 \%, 29.89 \%$, and $19.84 \%$ at 5,3 , and 1 DAS, respectively. Furthermore, the highest mean population was observed 22.13a on 1 DAS against Cypermethrin insecticide. In contrast, the lowest mean population was displayed $0.43 \mathrm{c}$ on $7 \mathrm{DAS}$ against Dimethoate insecticide. In control, the highest average population was recorded 26.13a at 7 DAS and the lowest population was seen $21.45 \mathrm{a}$ at $3 \mathrm{DAS}$. The ANOVA shows a significant difference $(\mathrm{P}<0.05)$ between various intervals and insecticides.

Our results agreed with [21] who reported that the Dimethoate proved as an extremely effective insecticide and showed $56.34 \%$ population reduction of aphid as compared to Acetamiprid (54.51\%) and Imidacloprid $(50.94 \%)$ on 7 DAS, respectively. According to [27] who reported that the application of Bifenthrin insecticide was showed maximum reduction followed by Imidacloprid at 3 DAS. Similarly, Dimethoate (59.59\%) and Imidacloprid (54.10\%) insecticides showed the highest reduction followed by Acetamiprid (55.11\%) insecticide at 3 DAS [21]. We agreed with [28] who said that the dose of Cypermethrin insecticide displayed the lowest reduction followed by Imidacloprid during various intervals against aphids, respectively.

Table 1. Effect of different insecticides on the population of Bemisia tabaci at different intervals in greenhouse

\begin{tabular}{|c|c|c|c|c|}
\hline \multirow{2}{*}{ Treatments } & \multicolumn{4}{|c|}{ Post-treatment / leaf } \\
\cline { 2 - 5 } & $\mathbf{1 ~ D A S}$ & 3 DAS & 5 DAS & 7 DAS $^{\text {DAS }}$ \\
\hline \multirow{2}{*}{ Imidacloprid } & $3.78^{\mathrm{c}}$ & $1.05^{\mathrm{d}}$ & $0.73^{\mathrm{d}}$ & $0.35^{\mathrm{c}}$ \\
& $(71.07)$ & $(91.95)$ & $(94.44)$ & $(96.36)$ \\
\hline \multirow{2}{*}{ Cypermethrin } & $7.18^{\mathrm{b}}$ & $6.43^{\mathrm{b}}$ & $5.88^{\mathrm{b}}$ & $5.13^{\mathrm{b}}$ \\
& $(45.02)$ & $(50.77)$ & $(54.98)$ & $(54.98)$ \\
\hline \multirow{2}{*}{ Bifenthrin } & $5.98^{\mathrm{bc}}$ & $4.53^{\mathrm{c}}$ & $2.88^{\mathrm{c}}$ & $1.08^{\mathrm{c}}$ \\
& $(54.21)$ & $(65.33)$ & $(77.97)$ & $(91.76)$ \\
\hline \multirow{2}{*}{ Dimethoate } & $3.68^{\mathrm{c}}$ & $1.23^{\mathrm{d}}$ & $0.83^{\mathrm{d}}$ & $0.48^{\mathrm{c}}$ \\
& $(71.84)$ & $(90.61)$ & $(93.68)$ & $(96.36)$ \\
\hline \multirow{2}{*}{ Acetamiprid } & $4.78^{\mathrm{c}}$ & $2.10^{\mathrm{d}}$ & $1.48^{\mathrm{d}}$ & $1.05^{\mathrm{c}}$ \\
& $(63.41)$ & $(83.91)$ & $(88.70)$ & $(91.95)$ \\
\hline (Control) & $11.75^{\mathrm{a}}$ & $9.93^{\mathrm{a}}$ & $11.63^{\mathrm{a}}$ & $13.28^{\mathrm{a}}$ \\
\hline
\end{tabular}

Different letters within a column indicate a significant difference (Fishers's Protected LSD test: P<0.05); DAS: Days After Spray; Figures in the parenthesis are percent reduction over control 


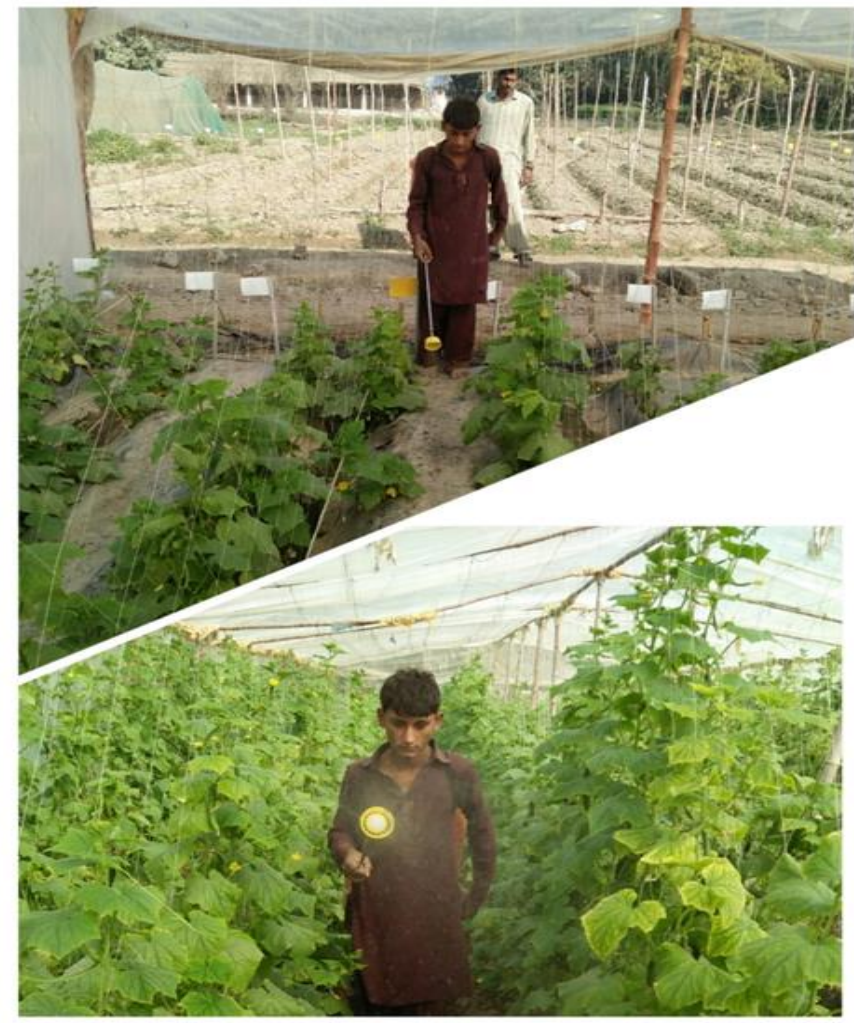

Figure 3. Spray of different insecticides on cucumber

Table 2. Effect of different insecticides on the population of Aphis gossypii at different intervals in greenhouse

\begin{tabular}{|c|c|c|c|c|}
\hline \multirow{2}{*}{ Treatments } & \multicolumn{4}{|c|}{ Post-treatment/leaf } \\
\cline { 2 - 5 } & $\mathbf{1 ~ D A S}$ & $\mathbf{3 ~ D A S}$ & $\mathbf{5 ~ D A S}$ & 7 DAS \\
\hline \multirow{2}{*}{ Imidacloprid } & $6.43^{\mathrm{bc}}$ & $3.38^{\mathrm{b}}$ & $2.95^{\mathrm{c}}$ & $2.30^{\mathrm{c}}$ \\
& $(76.72)$ & $(87.77)$ & $(89.31)$ & $(91.67)$ \\
\hline \multirow{2}{*}{ Cypermethrin } & $22.13^{\mathrm{a}}$ & $19.35^{\mathrm{a}}$ & $18.13^{\mathrm{b}}$ & $16.08^{\mathrm{b}}$ \\
& $(19.84)$ & $(29.89)$ & $(34.33)$ & $(41.76)$ \\
\hline \multirow{2}{*}{ Bifenthrin } & $9.65^{\mathrm{bc}}$ & $5.18^{\mathrm{b}}$ & $2.73^{\mathrm{c}}$ & $2.28^{\mathrm{c}}$ \\
& $(65.04)$ & $(81.23)$ & $(90.13)$ & $(91.76)$ \\
\hline \multirow{2}{*}{ Dimethoate } & $6.15^{\mathrm{c}}$ & $2.58^{\mathrm{b}}$ & $0.98^{\mathrm{c}}$ & $0.43^{\mathrm{c}}$ \\
& $(77.72)$ & $(90.67)$ & $(96.47)$ & $(98.46)$ \\
\hline \multirow{2}{*}{ Acetamiprid } & $11.48^{\mathrm{b}}$ & $6.25^{\mathrm{b}}$ & $2.23^{\mathrm{c}}$ & $1.48^{\mathrm{c}}$ \\
& $(58.42)$ & $(77.36)$ & $(91.94)$ & $(94.66)$ \\
\hline (Control) & $23.08^{\mathrm{a}}$ & $21.45^{\mathrm{a}}$ & $23.63^{\mathrm{a}}$ & $26.13^{\mathrm{a}}$ \\
\hline
\end{tabular}

Different letters within a column indicate a significant difference (Fishers's Protected LSD test: P<0.05); DAS: Days After Spray; Figures in the parenthesis are percent reduction over control

\section{Conclusion}

It is concluded that the population of $B$. tabaci was highly reduced after 7 DAS when the spray of Imidacloprid and Dimethoate insecticides. While Acetamiprid and Bifenthrin insecticides were also showed a high reduction in the population. Similarly, the highest reduction $\%$ of $A$. gossypii was observed after 7 DAS when the application of Dimethoate insecticide as compared to Acetamiprid, Bifenthrin, and Imidacloprid insecticides, respectively. The least population reduction $\%$ of $B$. tabaci and A. gossypii 
was recorded after 7 DAS when the spray of Cypermethrin insecticide.

\section{Author's contributions}

Conceived and designed the experiments: FA Rustamani \& A Bukero, Performed the experiments: FA Rustamani, Analyzed the data: FA Rustamani, FA Rustamani \& SA Nahiyoon, Contributed materials/ analysis/ tools: SA Nahiyoon, AA Bukero, D Kumar \& Chetram, Wrote the paper: FA Rustamani \& A Bukero.

\section{References}

1. Khan Z, Shah AH, Gul R, Majid A, Khan U \& Ahmad H (2015). Morphoagronomic characterization of cucumber germplasm for yield and yield associated traits. Int $J A g r$ \& Agric Res 6(1): 1-6.

2. Maurya GP, Pal V, Singh GP \& Meena LK (2015). An economic analysis of cucumber cultivation in Sultanpur District of Uttar Pradesh (India). Int $J$ Agr Sci \& Res 5(1): 23-28.

3. Tatlioglu T (1997). Cucumber (Cucumis sativus L.) in: Kailov, $\mathrm{G}$ and BoBergn (eds.), Genetic improvement of vegetable crops. Oxf Perg Pr 197227.

4. Khan Z, Shah AH, Gul R, Majid A, Khan U \& Ahmad H (2015). Morphoagronomic characterization of cucumber germplasm for yield and yield associated traits. Int $J A g r$ \& Agric Res 6(1): 1-6.

5. Maurya GP, Pal V, Singh GP \& Meena LK (2015). An economic analysis of cucumber cultivation in Sultanpur District of Uttar Pradesh (India). Int $\mathrm{Jr}$ Agr Sci \& Res 5(1): 23-28.

6. Sanjeev K, Patel NB, Saravaiya SN \& Desai KD (2015). Economic viability of cucumber cultivation under NVPH. Afr J Agri Res 10(8): 742-747.

7. Government of Pakistan (2016). External trade statistics. Stat Bur Pak, Islamabad.

8. Shaheen S, Anwar S \& Hussain Z (2011). Technical efficiency of offseason cauliflower production in Punjab. J Agri Res 49(3): 391-406.
9. Food \& Agriculture Organization (2016). Food \& Agri Org Uni Nat. Available on http://faostat3.fao.org.

10. Zhang GF, Lu ZC \& Wan FH (2007). Detection of Bemisia tabaci (Homoptera: Aleyrodidae) remains in predator guts using a sequencecharacterized amplified region marker. Ent Exp Et Appl 123(1): 81-90.

11. Wan FH, Zhang GF, Liu SS, Luo C \& Chu D (2009). Invasive mechanism and management strategy of Bemisia tabaci (Gennadius) biotype B: Progress Report of 973 Program on Invasive Alien Species in China. Sci Chi \& LfSci 52(1): 88-95.

12. Naranjo SE \& Ellsworth PC (2009). The contribution of conservation biological control to integrated pest control of Bemisia tabaci in cotton. $J$ Biol Con 51(3): 458-470.

13. Torkamand M, Heidaria A, Ghajarieh H \& Faravardeh L (2013). Comparison of susceptibility of melon aphid populations, Aphis gossypii Glover (Hemiptera: Aphididae), from seven regions in Iran to pirimicarb and Malathion. J Cr Pr 2(2): 183-192.

14. Rahsepar A, Haghani M, SedaratianJahromi A, Ghane-Jahromi M \& Farrar N (2016). Different cucumber varieties could affect biological performance of cotton aphid, Aphis gossypii (Hemiptera: Aphididae), a case study at laboratory condition. J Ent 37(21): 353 364.

15. Blackman RL \& Eastop VF (2000). Aphids on the World's crops. An identification and information guide. $2^{\text {nd }}$ Edi John Wiley \& Sons, Chichester 414.

16. Wang SL, Zhang YJ, Li RM, Wu QJ \& $\mathrm{Xu}$ BY (2011). Biotype and resistance status of whitefly Bemisia tabaci in Beijing and Hunan areas. Ch J Appl Ent 48(2): 27-31.

17. El-Seady AA (2009). Effect of Imidacloprid on early season sap sucking insects in relation to analysis of its residues in cotton plants. $J$ Agr \& 
Sci, Mansoura Uni 34(5): 5357-5363.

18. El-Zahi SE \& Aref SA (2011). Field evaluation of recommended insecticides to control bollworms on cotton aphid, Aphis gossypii (Glover) and their side effect on associated predators. J Pes Cont \& Env Sci 19(1): 55-68.

19. Statistix (2006). Statistix 8.1 user guide, version 1.0. Analytical Software, P.O Box 12185, Tallahassee FL 32317 USA. Copyright (C) 2006 by Analytical Software.

20. Abbott WS (1925). A method of computing the effectiveness of an insecticide. J Ecno \& Ent 18: 265-267.

21. Shivanna BK, Gangadhara NB, Nagaraja R, Basavaraja MK, Swamy CMK \& Karegowda C (2011). Bioefficacy of new insecticides against sucking insect pests of transgenic cotton. Inter J Sci \& Nat 2(1): 79-83.

22. Sujatha B \& Bharpoda TM (2017). Evaluation of insecticides against sucking pests grown during kharif. Inter J Cur Mic \& Appl Sci 6(10): 12581268.

23. Chang BH, Lanjar AG, Solangi AW, Rajput A, Rais MUN \& Rais N (2016). Evaluation of different insecticides against sucking insect pest on sunflower crop. Eur Aca Res 4(1): 188206.

24. Awan DA \& Mushtaq AS (2012). Comparative efficacy of different insecticides on sucking and chewing insect pests of cotton. Aca Res Inter 3(2): 210-217.

25. Wagh BM, Pagire KS, Thakare DP \& Birangal AB (2017). Management of sucking pests by using newer insecticides and their effect on natural enemies in tomato (Lycopersicon esculentum Mill.). Inter J Cur Micr \& App Sci 6(4): 615-622.

26. Jha SK \& Kumar M (2017). Relative efficacy of different insecticides against whitefly, Bemisia tabaci on tomato under field condition. $J$ Ent \& Zoo Stud 5(5): 728-732.

27. Amer M, Aslam M, Razaq M \& Shad SA (2010). Effect of conventional and neonicotinoid insecticides against aphids on canola (Brassica napus L.) at Multan and Dera Ghazi Khan. Pak J Zool 42(4): 377-381.

28. Roy SK, Ali MS, Mony FTZ, Islam MS \& Matin MA (2014). Chemical control of whitefly and aphid insect pest of Frenchbean (Phaseolus vulgaris L.). J Biosci \& Agri Res 2(2): 69-75. 